Recebido em: 21 Abr. 2017 Aprovado em: 22 Jun. 2017 Publicado em: 12 Set. 2017

DOI: https://doi.org/10.18554/rt.v10i1.2102

v. 10 n. 1 - Jan. / Jun. 2017

\title{
A EXPERIÊNCIA DE MESTRANDOS COM A PESQUISA EDUCACIONAL E OS SABERES EM TORNO DA CONSTRUÇÃO DE SEU OBJETO DE ESTUDO
}

\author{
THE EXPERIENCE OF MASTER'S DEGREE STUDENTS WITH EDUCATIONAL \\ RESEARCH AND THE KNOWLEDGE CONCERNING THE CONSTRUCTION OF THEIR \\ OBJECT OF STUDY
}
LA EXPERIENCIA DE LOS ESTUDIANTES DE MÁSTER CON LA INVESTIGACIÓN EDUCATIVA Y EL CONOCIMIENTO RELATIVO A LA CONSTRUCCIÓN DE SU OBJETO DE ESTUDIO

\section{RESUMO}

Messias Dieb Pollyana Nobre Melo Fernando Antônio Batista dos Santos Júnior E-mail: mhdieb@gmail.com Universidade Federal do Ceará - UFC

Discutimos a relação de mestrandos na área da Educação com a atividade de pesquisa, tendo como recorte o processo de construção de seus objetos de estudo. A teoria da Relação com Saber de Charlot (2000) foi usada como fundamentação para análise dos dados. Fizemos o registro de entrevistas semiestruturadas com 12 (doze) alunos dos Programas de Pós-Graduação em Educação da Universidade Federal do Ceará (UFC) e 2 (dois) da Universidade Estadual do Ceará (UECE), situados, respectivamente, nos campi do Benfica e do Itaperi, em Fortaleza - CE. A análise das entrevistas mostrou que, para os mestrandos recém-ingressos no curso de pósgraduação, a construção do objeto de estudo está pautada na coerência e na viabilidade entre as orientações teóricas e metodológicas da investigação pretendida, assim como nas experiências pedagógicas cotidianas e no desejo do pesquisador em relação a um determinado tema de seu interesse.

PALAVRAS-CHAVE: Pesquisa no campo educacional. Relação com o saber. Objeto de estudo.

\begin{abstract}
In this paper, we reflect on the relationship of master's degree students with the research activity in the educational field, considering specifically the construction of their objects of study. Charlot's ideas (2000) about the relationship to the knowledge were the theoretical foundation for the analysis of data. Our study involved semi-structured interviews with students from two Graduate programs in Education in Brazil: 12 (twelve) at Federal University of Ceara (UFC) and 2 (two) at State University of Ceara (UECE). The analysis of data has shown that, for the students, the construction of the object of study is aligned with the coherence and viability between the theoretical and methodological orientations for the investigation and day-by-day pedagogical experiences, and the researcher's desire concerning to a certain theme of interest as well.
\end{abstract}

KEYWORDS: Research in educational field. Relationship with knowledge. Object of study.

\section{RESUMEN}

En este trabajo reflexionamos sobre la relación de los estudiantes de máster con la actividad de investigación en el campo educativo, considerando específicamente la construcción de sus objetos de estudio. Las ideas de Charlot (2000) sobre la relación con el conocimiento fueron la base teórica para el análisis de los datos. Nuestro estudio envolvió entrevistas semiestructuradas con estudiantes de dos programas de postgrado en Educación en Brasil: 12 (doce) en la Universidad Federal del Ceará (UFC) y 2 (dos) en la Universidad Estadual del Ceará (UECE). El análisis de los datos ha mostrado que, para los estudiantes, la construcción del objeto de estudio está alineada no solo con la coherencia y viabilidad entre las orientaciones teóricas y 
metodológicas para la investigación sino también con las experiencias pedagógicas cotidianas y el deseo del investigador en relación con un cierto tema de interés.

PALABRAS-CLAVE: Investigación en campo de campo. Relación con el conocimiento. Objeto de estudio.

\section{INTRODUÇÃO}

O presente artigo se configura como parte de uma pesquisa maior intitulada "A mobilização em torno do saber-pesquisar: escolhas e expectativas do mestrando na área de Educação". Essa pesquisa foi desenvolvida e coordenada pelo primeiro autor, vinculado ao Departamento de Fundamentos da Educação da Universidade Federal do Ceará (UFC), com a colaboração de bolsistas de iniciação cientifica (segundo e terceiro autores deste trabalho). Trata-se de um estudo que tem como objetivo analisar a relação de mestrandos com a atividade de pesquisa no campo da Educação, partindo das escolhas teórico-metodológicas feitas pelos mestrandos e das expectativas levantas por esses sujeitos referentes à conclusão do seu trabalho de pesquisa na área educacional.

Para o desenvolvimento de nosso trabalho, elegemos como sujeitos de pesquisa os estudantes que acabam de adentrar a Pós-Graduação stricto sensu em Educação devido ao fato de que estes ainda possuem muitas dúvidas e incertezas sobre o "fazer" da pesquisa, apesar de alguns deles já trazerem conhecimentos adquiridos em projetos de pesquisa anteriores, vivenciados na iniciação científica ou em cursos de pós-graduação lato sensu. Com base nessa definição, focaremos, no presente artigo, apenas um dos objetivos específicos do projeto de pesquisa já mencionado, no parágrafo anterior, que é o de compreender o sentido que esses aprendizes de pesquisador atribuem ao fazer-pesquisa, analisando, de forma mais aprofundada, a relação entre as escolhas teórico-metodológicas e os objetivos propostos por eles nos projetos de pesquisa que foram selecionados para o curso de mestrado.

Nossa suposição é a de que, ao compreendermos o processo de construção do objeto de estudo desses sujeitos, materializado na relação entre as escolhas teórico-metodológicas e os objetivos propostos para o trabalho, poderemos captar os sentidos que eles atribuem ao saber-pesquisar. Para nos ajudar nessa tarefa, buscamos como fundamentação teórica básica a teoria defendida por Charlot (2000), que versa sobre os processos de aprendizagem em que os sujeitos se engajam e, assim, constroem uma relação de sentido com o saber a ser apreendido. Portanto, a partir dos postulados teóricos elaborados por esse autor, analisamos os saberes construídos pelos sujeitos sobre a atividade de pesquisa no campo educacional, saberes estes que nos foram apresentados em entrevistas semiestruturadas realizadas, com eles, assim que foram selecionados para o curso de Mestrado em Educação nas duas maiores universidades públicas do estado do Ceará.

Assim sendo, como forma de organização das informações, discutiremos, na sequência, o tema da pesquisa educacional, relacionando algumas ideias relativas a esse tema com os postulados da teoria da relação com o saber (CHARLOT, 2000). Em seguida, enunciaremos a forma como organizamos a pesquisa, apresentando os procedimentos metodológicos escolhidos para a escolha dos sujeitos, a construção e a análise dos dados. Por 
fim, apresentaremos os resultados da análise das entrevistas feitas com os mestrandos e as nossas considerações finais sobre o que foi discutido durante a análise.

\section{REFERENCIAL TEÓRICO}

Para falarmos sobre a atividade de pesquisa, é necessário dizer que a concebemos como um processo de construção do conhecimento. Assim sendo, essa compreensão pode ser aqui apresentada nas palavras de Mattos e Vieira (2002, p. 21) que, como nós, veem na pesquisa uma atividade científica "que nos permite a aproximação e o entendimento da realidade de que investigamos, e, além disso, nos fornece elementos para possibilitar nossa intervenção no real". Com base nessa definição, podemos afirmar que toda pesquisa, em especial aquela no campo das humanidades, possui uma forte relação com a sociedade, já que se trata de um processo dinâmico e interativo, o qual permite uma reflexão sobre a realidade e, por conseguinte, possibilita o desenvolvimento de maneiras de solucionar problemas para o desenvolvimento social. Por esta razão, a pesquisa sempre surge a partir de questões levantas nas vivências e experiências do próprio pesquisador com o mundo do qual ele participa, construindo-o e por ele sendo construído.

No que concerne à pesquisa educacional, esses aspectos se tornam ainda mais salientes devido ao fato de que ela se encontra no campo das ciências humanas e sociais. Ao pesquisar sobre determinado assunto, o sujeito pesquisador estará expondo a sua interpretação acerca de determinado fato social, podendo ser confrontado por outros estudiosos que não possuem a sua mesma familiaridade com o assunto. Portanto, mesmo sendo guiada por princípios e padrões de atividades caracteristicamente cristalizados pelo universo científico, toda pesquisa implica sempre um modo particular de o pesquisador se apropriar da realidade.

Nessa perspectiva, ao empreender uma atividade científica, o pesquisador vai sempre, de modo singularizado, orientar-se pelas disposições reguladas de um habitus científico que é, segundo Bourdieu (1996, p. 88), “em parte, produto da incorporação da necessidade imanente do campo científico e das limitações estruturais exercidas por esse campo em um momento dado do tempo". Isso se justifica porque,

o pesquisador é um dos principais instrumentos da pesquisa [e], sendo parte integrante da investigação, sua compreensão se constrói a partir do lugar sóciohistórico no qual se situa e depende das relações intersubjetivas que estabelece com os sujeitos com quem pesquisa (FREITAS, 2003, p. 28). 
Logo, a ação de pesquisar implica uma oportunidade na qual o pesquisador pode aprender muito, não apenas sobre o que se perguntou no início do processo, mas também aprender sobre si mesmo a partir da relação com os outros sujeitos com quem terá contato no processo de investigação.

Segundo Gatti (2002), a pesquisa educacional possui uma multiplicidade de problemas, devendo o ato de estudar sobre essa multiplicidade ser considerado como o ponto da partida e o ponto da chegada de todo o trabalho do pesquisador. De modo mais específico, a autora afirma que o pesquisador em Educação deve buscar refletir sobre pontos importantes, que caracterizam e estruturam essa área, com o objetivo de promover meios que tragam melhorias tanto para o próprio campo educacional como para toda a vida social. Isto se justifica porque se trata de um campo que envolve

a interação complexa de todos os fatores implicados na existência humana, desde o
nosso corpo até as nossas ideologias, num conjunto único, porém, em constante
processo simultâneo de consolidação, contradição e mudança. Com tal âmbito de
preocupação, os pesquisadores em Educação fazem escolhas entre um dos múltiplos
caminhos que se aproximam da compreensão desse fenômeno, escolhendo, também,
um ângulo de abordagem. (GATTI, 2002, p. 13).

Com base no que explicita a autora, na citação acima, é importante assinalar que também fizemos nossas escolhas acerca de uma abordagem para estudar a relação dos mestrandos com a atividade de pesquisa no campo da Educação. Essa abordagem é a da relação com o saber (CHARLOT, 2000), a qual orienta o pesquisador na compreensão sobre o engajamento dos sujeitos nos inúmeros processos de aprendizagem com os quais eles se deparam ao longo da vida, por meio do que os mobiliza para esse engajamento e dos sentidos que atribuem a tais processos.

O delineamento dessa abordagem foi feito por Charlot (2000; 2001; 2005), filósofo francês que passou a se dedicar à pesquisa de relevantes questões no campo educacional, a partir do estudo da relação que alunos da periferia desenvolvem com escola e com o saber que ela propaga. Na esteira de suas pesquisas, Charlot (2005, p. 16) problematiza a correlação que geralmente é feita entre a posição social desses indivíduos e o êxito (ou o fracasso) que lhes atribui a passagem pela escola. Ao criar a equipe de pesquisa ESCOL (Educação, Socialização e Coletividades Locais), o autor desenvolveu a teoria da "relação com o saber", baseado mais especificamente na premissa de que "o homem está [sempre] em busca de significados, de sentidos [para tudo o que faz]". Logo, é a partir de suas experiências que o 
indivíduo vai atribuindo sentido aos incontáveis objetos de aprendizagem com os quais se relaciona e, a partir dessas relações, construindo saberes.

No entanto, o processo de uma aprendizagem legítima somente acontece quando o sujeito se mobiliza, ou seja, quando ele é acionado internamente para o ato de aprender. Esse processo dinâmico e interno ao sujeito é denominado por Charlot (2000) de mobilização, o qual só ocorre quando o sujeito encontra algum sentido na sua relação com o saber a ser aprendido. Nesse contexto, o saber, que é produto do ato de aprender e que se manifesta pela linguagem, é produzido a partir da apropriação de um determinado conhecimento pelo sujeito, processo este que se manifesta pela e na verbalização de um sujeito acerca do que foi apropriado cognitivamente.

Isto ocorre não somente pelo conteúdo desse conhecimento, mas também, e principalmente, pelo sentido que tal conhecimento irá produzir para o sujeito. Em outros termos, o objetivo da aprendizagem deve coincidir com o elemento que a motiva. Assim, de acordo com Charlot (2005), a função do pesquisador não é buscar apenas os motivos, mas também compreender as diferentes relações que os aprendizes constroem com o saber, buscando entender os diferentes sentidos que eles igualmente revelam a respeito do ato de aprender.

Por esta razão, o mesmo autor afirma que

não se pode aprender sem mudar pessoalmente, porque, se estou aprendendo coisas que têm um sentido, vou mudar minha visão do mundo, minha visão da vida. [...] E se eu estiver aprendendo coisas que não têm nenhum sentido, não estou aprendendo e, por isso, vou esquecê-las depois [de uma] prova. (CHARLOT, 2005, p. 71).

Com base nessa perspectiva é que buscamos entender os significados que o "fazer pesquisa" tem para os mestrandos na área da Educação. Em outros termos, buscamos também conhecer os saberes que foram sendo construídos, por eles, acerca da atividade de pesquisa ao longo de suas interações nos espaços educativos em que atuaram. Isto se justifica porque, de acordo com Charlot (2000), a relação com o saber se inicia na apropriação de uma informação por parte do sujeito, tornando essa informação um conhecimento. Posteriormente, ao se relacionar com outros sujeitos, o indivíduo passa a compartilhar o que sabe e a confrontar o seu conhecimento com o do outro, que possui outra relação com o mundo, havendo, assim, uma relação de confrontos interpessoais. Portanto, para o autor, o saber expressa concepções e 
interpretações construídas a partir das experiências vividas por cada indivíduo em sua relação com o mundo.

Mediante os problemas educacionais enfrentados em nosso país, a prática da pesquisa tende, portanto, a possibilitar o conhecimento, a explicação e a compreensão de uma dada realidade, bem como afirmar-se como um compromisso político por parte de quem a desenvolve. Desse modo, inferimos que, ao compreendermos os significados que os mestrandos dão ao objeto de seu estudo e à própria atividade de fazer pesquisa, poderemos entender igualmente os elementos que sustentam a sua mobilização acerca desta atividade, a qual se traduz pelo desejo expresso de que ela poderá trazer melhorias para a área da Educação. Logo, compreender o sentido do "fazer-pesquisa" para os mestrandos em Educação é relevante não apenas pelo caráter acadêmico do qual se reveste uma investigação dessa natureza, mas também pelo relevo social e político que esta atividade incorpora em sua composição.

\section{MATERIAIS E MÉTODOS}

A pesquisa desenvolvida foi inspirada nas características da Perspectiva Qualitativa, utilizando como técnica para a construção de dados a entrevista semiestruturada. Antes de irmos a campo, foram realizados grupos de estudo envolvendo o coordenador do projeto e os bolsistas colaboradores da pesquisa. Os encontros desse grupo tinham como foco a discussão sobre os principais postulados da teoria da relação com o saber, os quais embasaram a pesquisa e fundamentaram a formulação das questões que seriam feitas diretamente aos entrevistados.

Os sujeitos entrevistados foram 12 (doze) alunos recém-selecionados, à época, pelo Programa de Pós-Graduação em Educação da UFC e 2 (dois) alunos selecionados pelo Programa de Pós-Graduação em Educação da UECE. Esses dois programas estão situados, respectivamente, nos campi do Benfica e do Itaperi, em Fortaleza - CE, onde fomos ao encontro dos sujeitos contatando, inicialmente, as coordenações para que nos fornecessem o endereço da lista de e-mails dos estudantes, a fim de empreendermos os primeiros contatos. Após algumas trocas de e-mail, e muita negociação sobre local e horário para a realização das entrevistas, finalmente conseguimos acordar o nosso tempo disponível com o dos novos mestrandos. 
Na busca de compreender a relação do pesquisador recém-ingresso no Mestrado em Educação com o saber pesquisar, focamos nos sentidos do "fazer-pesquisa" para eles, a partir das escolhas teórico-metodológicas que perpetraram para a construção dos objetos de estudo em seus trabalhos. Por objeto de estudo compreendemos, a partir das ideias de Sá (1998), o resultado de um processo de articulação entre um fenômeno, estranhado e percebido pelo pesquisador, e a(s) abordagem(ens) teórico-metodológica(s) com a(s) qual(is) o pesquisador irá operar para a compreensão deste fenômeno. No caso de nosso estudo, buscamos compreender como se deu esse processo de articulação (e com qual sentido para os estudantes), a partir das ações empreendidas por eles (concernentes aos projetos de pesquisa que apresentaram na seleção para o curso de Mestrado em Educação).

Para isso, elaboramos um roteiro de entrevista, com possibilidades de flexibilização a partir do que o entrevistado fosse respondendo, surgindo novos questionamentos e assuntos diversos, conforme o entendimento da técnica de entrevista semiestruturada. Assim, as entrevistas foram realizadas nos campi acima mencionados, de acordo com a disponibilidade dos próprios entrevistados, em horários agendados previamente via e-mail e/ou ligações telefônicas, visto que nosso grau de proximidade com eles já nos permitia a ter acesso a seus números de aparelho celular. Os diálogos decorrentes das entrevistas foram gravados em sistema de áudio MP3 para transcrição posterior, a qual foi realizada pelos próprios bolsistas da pesquisa.

Após a transcrição das entrevistas, demos início a um período de leitura e análise individual dos dados, relacionando o registro das falas nas entrevistas com os objetivos específicos da pesquisa. Essa análise individual foi posteriormente condensada em uma análise geral dos bolsistas com o coordenador da pesquisa. Para nortear a análise apresentada, neste artigo, fomos guiados principalmente pelas seguintes questões: Como os mestrandos fizeram as escolhas teórico-metodológicas para seus trabalhos de pesquisa? Que relações existem entre essas escolhas e os objetivos propostos para a sua pesquisa? Na finalização do trabalho de análise, foram realizados encontros entre o orientador e os bolsistas do projeto para a discussão sobre os resultados encontrados.

Cada um trouxe a sua análise individual para ser discutida em grupo e, ao final do encontro, foram traçadas conclusões mais gerais e que buscavam sintetizar e uniformizar as discussões feitas pelo grupo. Nesse sentido, o processo de análise foi orientado por um mesmo conjunto de questões norteadoras que foram seguidas por cada um dos bolsistas, os 
quais colocavam em uma tabela os resultados referentes aos temas suscitados por cada uma dessas questões. Nos encontros em grupo, cada questão era debatida em conjunto, à luz dos conceitos da teoria da relação com o saber, a fim de que os pesquisadores (professor/orientador e bolsistas) chegassem a um consenso mínimo na interpretação dos dados. Essas duas fases da análise (individual e em grupo) serviram, portanto, para que cada bolsista pudesse desenvolver uma reflexão e uma apropriação dos dados, ampliando essa apropriação por meio do debate no grupo.

Para a apresentação desses resultados, a seguir, as identificações com os nomes reais dos sujeitos entrevistados foram omitidas, sendo estas substituídas por nomes fíctícios seguidos da sigla da instituição a que pertencem.

\section{ANÁLISE DOS DADOS E RESULTADOS}

A análise dos dados nos revelou que grande parte dos mestrandos formulou as suas escolhas teórico-metodológicas tendo como base as experiências vividas dentro da universidade, no período da Graduação. Em sua maioria, os projetos dos mestrandos foram sendo construídos a partir de questões levantas na relação que estes faziam entre o que aprenderam nas aulas da Graduação em Pedagogia e sua prática de ensino na escola, durante os estágios, tendo alguns, inclusive, já como docentes. Esse fato nos rendeu boas discussões sobre a necessidade de os professores das licenciaturas estarem atentos ao que já sabem e ao que vivenciam os estudantes no interior das escolas, bem como às possibilidades de essas experiências serem pontos de partida para a formulação de questões de pesquisa. Ao atentarem para isso, os professores universitários, especialmente nas licenciaturas, podem, portanto, dar frutíferas contribuições à formação não apenas docente, mas também científica dos graduandos.

Esse é o caso da mestranda Mariana, formada em Pedagogia pela UFC, no curso noturno. A entrevistada nasceu no interior do Maranhão, em Santa Luzia. Atualmente residindo em Fortaleza, Mariana atua como professora em uma Instituição de Ensino Municipal. Segundo o que nos relatou, sua relação com a pesquisa se iniciou ainda na Graduação, quando ela cursava a disciplina Educação Infantil, temática pela qual teve interesse de aprofundar e pesquisar na pós-graduação, como podemos observar pela sua fala a seguir: 
Eu quis fazer todas as disciplinas do núcleo da Educação Infantil porque eu gostei e estava encontrando as respostas que eu me questionava a noite, nas aulas que eu tinha no curso de Pedagogia e que eu não encontrava. Então, aí eu fiz todas as disciplinas do curso pra Educação Infantil, e tive a oportunidade de ser bolsista de uma professora, no programa de formação de professores para a Educação Infantil. Então, foi na oportunidade de estar como bolsista nesse programa que eu me aproximei do Mestrado, de querer estudar mais, de ver aquele mundo de pesquisa, de conhecimento mais intenso, porque eu participava das formações de todos os momentos de formações que o curso possibilitava aos professores. Eu estava desde o planejamento dos professores daqui da Universidade, na avaliação dos encontros. Então, eu acho que isso foi instigando em mim a vontade de querer conhecer mais, a vontade de querer ser mais... então, foi, por isso, que eu me aproximei. Eu tenho a plena convicção disso.” (Mariana/UFC).

Como podemos perceber, o envolvimento dos estudantes com outras atividades, além daquelas típicas da sala de aula, pode levá-los a descobrir explicações teóricas para algumas questões de sua prática e a desenvolver o interesse em ampliar o que já sabem por meio de uma formação mais verticalizada.

O motivo da ênfase, dada pela entrevistada às disciplinas de Educação infantil, está no fato de que os cursos de Pedagogia na UFC, diurno e noturno, passaram, a partir de 2007, a enfatizar disciplinas voltadas para áreas diferenciadas. Enquanto o curso diurno centrava suas disciplinas na formação do professor de Educação infantil, o curso noturno formava para a Educação de jovens e adultos. Por este motivo, como Mariana pertencia ao curso noturno, suas questões sobre a Educação infantil só passaram a ter alguma resposta quando ela se matriculou em disciplinas do turno diurno.

Além disso, a mestranda ressalta a oportunidade de ter sido bolsista de uma professora que estudava os mesmos temas de seu interesse. Segundo suas próprias palavras, esse foi um importante e decisivo fator que a impulsionou rumo à atividade pesquisa, a qual é significada pela mestranda como uma oportunidade de "conhecer mais sobre o assunto que tanto lhe interessa", bem como de "ser mais" do que uma simples executora de tarefas docentes. A expressão "conhecer mais sobre o assunto" implica, ao nosso ver, ter acesso a referências teóricas consistentes que pudessem lhe trazer subsídios analíticos para as questões de sua prática educativa. Assim sendo, a experiência como bolsista foi um importante elemento de mobilização para Mariana, haja vista sua percepção sobre o frutífero e sempre necessário encontro entre teoria e prática, especialmente no seu caso que já trabalhava com Educação Infantil.

Outra experiência parecida com a de Mariana foi a da mestranda Geovana, também formada em Pedagogia pela UFC. Esta foi aluna-bolsista do Programa de Educação Tutorial 
(PET), o que a permitiu direcionar o seu interesse de pesquisa para as questões presentes na própria graduação, de modo mais específico, para a questão curricular do curso de Pedagogia.

\begin{abstract}
As coisas que mais me influenciaram nas minhas escolhas para o projeto foi essa questão de ter um olhar pra graduação, porque o grande objetivo do PET é melhorar a graduação. Então, o que o PET fez foi eu olhar pra graduação, não com os olhos de aluna, mas com um olhar de pesquisadora mesmo, de olhar e ver ali objetos de estudo, de coisas que deveriam ser analisadas, então, o PET fez isso por mim. E puxando pro lado do currículo, devido à professora que era a tutora, ela tem todo esse embasamento teórico voltado pro currículo, então, essas duas coisas acabaram me levando... Acho que o PET tem influência total nas minhas escolhas. (Geovana/UFC).
\end{abstract}

Como podemos observar, pela fala de Geovana, os conhecimentos formulados sobre a pesquisa, a escolha do tema e a apropriação dos processos teórico-metodológicos foram aprendidos especialmente na sua atuação como bolsista do PET.

Inicialmente, a mestranda ressalta a própria filosofia do PET que, segundo ela, é posta em curso visando ao início de uma formação para a atividade de pesquisa. Em seguida, a estudante lembra o incentivo e a tutoria da professora que orientou as atividades desse programa, em sua época, como sendo elementos mobilizadores de suas escolhas. A atuação da professora tutora influenciou não apenas as escolhas da mestranda sobre temas, como, por exemplo, relacionados ao Currículo, e que ela iria estudar no curso de mestrado, mas também as orientações teórico-metodológicas correspondentes. Por esta razão, inferimos que, assim como o PET, outras experiências como bolsista na graduação, tais como a Iniciação Científica (PIBIC) ou a monitoria na Iniciação à Docência (PIBID), tenham igualmente impulsionado e contribuído para que os mestrandos participassem de grupos de estudo e, a partir deles, construído seus projetos de pesquisa. Isso mostra, portanto, a relevância das experiências que temos de oportunizar aos estudantes em sua formação inicial e que o ajudarão nos níveis educacionais posteriores, caso queiram seguir adiante em sua formação acadêmica.

Em acréscimo, as falas apresentadas mostram o quanto a formação se torna ainda mais significativa quando ocorre por meio de atividades que envolvam a pesquisa. Outro fator bastante recorrente nas falas dos mestrandos entrevistados foi a importância dos grupos de estudos, construídos e promovidos pelos próprios estudantes, para as escolhas teóricometodológicas de seus projetos de pesquisa. Esse foi o caso de Jaqueline e Ricardo. Formados em Pedagogia pela UFC, atualmente os dois estão se especializando em Educação de Jovens e Adultos (EJA) no Sistema Prisional. O interesse de Jaqueline pelo mesmo tema de pesquisa da especialização (pós-graduação lato sensu) surgiu através dos grupos de estudos com seus 
colegas da Graduação. Apesar de pertencer ao mesmo grupo de estudo e de estudar no mesmo curso de especialização, Ricardo decidiu direcionar sua pesquisa para a área da História da Educação, especificamente, pesquisando os fatos históricos que marcaram a Faculdade de Educação (FACED) da Universidade Federal do Ceará (UFC).

Eu consegui descobrir claramente o que eu queria pesquisar dentro do grupo de estudo, com a ajuda dos outros. Isso pra mim foi muito enriquecedor: receber essa ajuda, pra mim e pra construção do meu objetivo. [...] A gente teve um momento no grupo que foi estudar metodologias, então, a gente foi pesquisar cada uma delas e, foi lendo, apresentando e decidindo: "olha, essa é a mais viável para fazer pesquisa de tal coisa, de tal forma"! Aí, a partir destas discussões, foi que eu fui entender que, ao meu ver, essa seria a melhor forma de eu fazer minha pesquisa. (Jaqueline/UFC).

Foi um grupo de amigos que se reuniu para estudar. A ideia inicial era a EJA, porque nós estávamos, aliás, estamos ainda numa especialização de EJA para o sistema prisional, e começamos a ler dois livros de Paulo Freire. Depois, nós fomos trabalhar em saber o que é pesquisa e as suas metodologias e os métodos a serem aplicados. (Ricardo/ UFC).

$\mathrm{Na}$ socialização com outros membros do grupo de estudo, isto é, na relação dos aspirantes ao lugar de pesquisador com outros sujeitos que perseguiam o mesmo objetivo, estes conheceram novos autores que tratavam sobre os temas que queriam estudar. Além disso, dividiram suas dúvidas e incertezas acerca da atividade de pesquisa, bem como descobriram novos métodos e técnicas a serem utilizadas de acordo com os objetivos a serem alcançados. Portanto, os grupos de estudo parecem ter sido uma importante fonte de saberes sobre a atividade de pesquisa, haja vista discutirem teorias que se relacionam com os interesses e objetivos de seus membros na pesquisa educacional, o que pode ajudar ainda na construção dos objetos de estudo.

Nesse percurso de escolhas, como vimos através da teorização de Charlot (2000) sobre a relação com o saber, parece que os objetivos que guiavam os estudantes estavam sempre coincidentes com seus motivos, o que tornou significativo todo o processo de envolvimento e de aprendizagem para eles. Isso se justifica, ainda mais, porque grande parte dos entrevistados revelou que o pesquisador necessita gostar do tema em foco para poder iniciar a sua pesquisa, ou seja, que é importante que ele desenvolva uma relação de identificação com o tema (o objeto a ser apreendido), embora alguns também tenham ressaltado que essa identificação precisa ser racionalizada. O entendimento acerca dessa racionalização nos leva a perceber que ela implica em decisões conscientes, ou seja, em uma relação epistêmica e não somente identitária (afetiva) com o saber, como afirma Charlot (2000). Em outros termos, implica que os estudantes defendem a necessidade de eles se 
perceberem "conhecedores" do que é preciso ser feito em termos de pesquisa, especialmente em relação à construção do objeto de estudo. Acerca desses aspectos, argumentaram Mariana, sobre a qual já falamos acima, Carla e Antônio, a seguir.

Antônio é graduado em História pela Universidade Regional do Cariri (URCA), no Ceará. Sendo natural de Juazeiro do Norte - CE, decidiu focar sua pesquisa no campo educacional para tentar transformar a realidade social de sua região, estudando os aspectos subjetivos, históricos e sociais que estão envolvidos no processo de formação dos indivíduos que nela habitam.

\begin{abstract}
A melhor maneira? Talvez por afinidade, é uma boa maneira, mas também por pesquisas que ainda não foram feitas. Não adianta você ter uma afinidade com o tema e ter milhares de livros e teses sobre aquele tema. Você deve ter uma certa credibilidade naquilo que faz. Você não pode fazer algo só porque um orientador quer, só porque a sociedade tá impondo aquilo como tema da moda. Você deve fazer aquilo com uma certa finalidade. Finalidade que está envolvida com você e com a Universidade também. (Antônio/UFC).
\end{abstract}

A identificação com o tema é traduzida no posicionamento de Antônio como uma espécie de "afinidade racionalizada". Em outros termos, isto implica dizer que a escolha do tema a ser estudado, e todas as demais escolhas a serem feitas a partir dele, esteja revestida de uma intencionalidade do pesquisador. Isso parece estar relacionado com o que pensa Charlot (2000; 2005) ao afirmar que, na relação com saber, não é o conteúdo isolado em si que motiva o aluno a estudar, e em nosso caso a pesquisar, mas a mobilização que impulsiona e sustenta o desejo de estudar e o sentido que aquele conhecimento tem para a sua prática. Portanto, podemos concluir que não basta apenas gostar do tema para escolhê-lo como ponto de partida para um objeto de estudo, mas que é preciso estabelecer outras relações nesse processo de escolha, para além dos motivos afetivos que possam ligar ambos: tema e pesquisador.

Sobre isso, manifestam-se também Mariana e Carla:

Eu fui trabalhar numa escola pública, em Mineirolândia (Ceará), e lá, naquele contexto, atuando como professora, foi que, refletindo, saiu o meu projeto de pesquisa. (Mariana/UFC).

Eu acho que uma forma boa de você escolher um tema pra pesquisar é aquilo que você gosta de estudar... e a reflexão sobre o que você vivencia. (Carla/UFC).

Com efeito, as experiências com a prática docente, exercida tanto profissionalmente como na situação de estágio, e as inciativas de formação voltadas para o exercício dessa prática, foram apontadas, quase que unanimemente, como fontes de inspiração e de 
mobilização para o desenvolvimento do objeto de estudo desses sujeitos, o que inclui não apenas a escolha do tema, mas também reflexões e decisões teórico-metodológicas. Além disso, a elaboração de um projeto de pesquisa precisa estar relacionada com as exigências acadêmicas que levem a sua aceitação como tal; aspecto este defendido na fala de Fernanda a seguir.

\begin{abstract}
A pesquisa-ação, eu tomei conhecimento dela na especialização. Aí, eu achei um livro muito bom [...], então, casou muito bem com o meu tema. É preciso a gente mostrar que tem um conhecimento adequado para realizar aquela pesquisa, ou pelo menos anunciar: - Eu não estou começando do zero, eu tenho uma bagagem. Digo adequado no sentido que a academia pede, entendeu? Tanto é que uma das coisas que mais me deixou triste foi que na seleção, é ... o meu projeto foi entregue no momento da seleção e quando fui estudar para a prova, eu tive contato com um autor e me apaixonei profundamente por ele, é perfeito. (Fernanda/UFC).
\end{abstract}

Fernanda, natural de Mossoró - RN, teve sua formação em História pela Universidade do Estado do Rio Grande do Norte (UERN), com especialização em Educação na área de Ensino e Currículo pela mesma universidade. Atualmente, Fernanda atua como professora de História do Instituto Federal (IF), na cidade de Currais Novos - RN. Seu interesse de pesquisa pela inclusão de jogos lúdicos no processo de ensino-aprendizagem surgiu na atuação como educadora, através de uma metodologia desenvolvida pela própria mestranda, ao utilizar os jogos de Role Playing Game (RPG) para trabalhar os assuntos didáticos da disciplina que leciona. Pelo que pudemos inferir, após o período do teste de seleção, a entrevistada modificou algumas partes de seu projeto, incluindo, como fundamentação, as ideias de um autor que ela estudou posteriormente à inscrição. A modificação se deu, portanto, porque essas ideias, provavelmente, deram maior consistência teórico-metodológica ao seu estudo.

Em adendo a essas declarações, os entrevistados afirmaram que a preparação para o teste de seleção de Mestrado possibilitou para eles o acesso a livros, teses, dissertações e artigos, todos referentes ao campo educacional, os quais podem ser interpretados também como uma importante fonte de construção de saberes acerca dos aspectos teóricometodológicos que vieram a orientar suas pesquisas. Apesar dessa dimensão mais "epistêmica" na relação da estudante com o trabalho de pesquisa, isso não implica dizer que as experiências e motivações individuais estejam ausentes. Ao contrário disso, como afiança Charlot (2000; 2001; 2005), é a partir das experiências e relações sociais construídas pelo indivíduo que ele se mobiliza e atribui sentido para as suas ações no mundo. Segundo esse mesmo autor, além da dimensão epistêmica, em qualquer relação com o saber sempre existirá 
uma dimensão identitária que é atravessada por uma dimensão social, haja vista o sujeito estar sempre socialmente posicionado.

Assim sendo, não é de se estranhar que Fernanda tenha classificado de "perfeito" o autor estudado para a seleção do mestrado e que ela tenha se apaixonado por suas ideias, considerando-as como sendo adequadas ao seu projeto de pesquisa e ao que a academia exige acerca desse gênero de texto. Ainda no que diz respeito a esse aspecto das exigências feitas pela academia, acerca da dimensão técnica que envolve um projeto de pesquisa, os mestrandos declararam que deve existir uma relação de coerência entre a fundamentação teórica e a metodologia a fim de que os objetivos propostos pela pesquisa sejam alcançados. Esse movimento está perfeitamente adequado ao que definimos como o processo de construção do objeto de estudo, segundo as ideias de Sá (1998). Ainda sobre este assunto, argumentaram Geovana, sobre quem já falamos acima, e Jorge.

Para mim, essa questão, a metodologia, leva duas coisas em consideração: o público-alvo e o objetivo da minha pesquisa, com base no que eu estudei na minha fundamentação teórica. (Geovana /UFC).

As tuas perguntas vão gerando os teus objetivos. Os teus objetivos vão gerar um, vamos dizer assim, campo de exploração teórica para que você possa entender o melhor modo de como responder aquelas perguntas iniciais ... e, para responder essas perguntas, você precisa formalizar as coisas em uma metodologia. (Jorge /UECE).

Como podemos inferir, pelas falas dos mestrandos Geovana e Jorge, os aspectos teórico-metodológicos devem seguir uma linha de afinidade com os objetivos do estudo a ser realizado.

Formado em Eletrotécnica pela antiga escola técnica do Ceará, Jorge se graduou em Pedagogia pela UECE. Buscando uma "formação mais humana", optou por pesquisar na área da Educação sobre assuntos que envolvam a Informática Educativa e o uso da tecnologia para trazer benefícios para a Educação e a vida social. No entendimento de Jorge, é preciso que o pesquisador compreenda a necessária articulação interna entre as seções que compõem o gênero projeto de pesquisa. Assim, ao dar ênfase à articulação entre as questões e os objetivos do estudo a ser desenvolvido, o entrevistado nos apresenta como ele se deu conta de um campo de exploração que poderia auxiliá-lo no delineamento mais preciso de seu objeto de estudo. Sobre esse campo de exploração, inferimos, pois, que ele se refere aos conceitos, teorias e métodos com os quais deverá operar para alcançar os objetivos propostos e, consequentemente, responder as questões que o geraram. Isto parece ser reforçado pelas 
palavras de Geovana, para quem a realidade e as características dos sujeitos com os quais irá trabalhar na pesquisa também influenciam nessas escolhas.

A partir dos aspectos que aqui analisamos, inferimos que a apropriação do saberpesquisar foi sendo gestada a partir de experiências com leituras e com programas de iniciação acadêmica na graduação, os quais se associam a iniciativas próprias de formação de grupos de estudo e a vivências como professor da Educação básica. Essas vivências ressoaram como elementos essenciais para a construção de seus projetos de pesquisa, os quais são representativos de um possível elemento transformador da realidade educacional, sendo este o principal desejo que dá sentido à mobilização dos sujeitos em relação à aprendizagem sobre a atividade de pesquisa.

\section{CONSIDERAÇÕES FINAIS}

Neste trabalho, buscamos analisar a relação entre as escolhas teórico-metodológicas feitas por mestrandos em Educação e os objetivos por eles propostos em seus projetos de pesquisa, a fim de compreender os sentidos que atribuem ao fazer-pesquisa nessa área. Foi um trabalho que nos proporcionou momentos ricos de formação acadêmica, visto que, a cada reunião da equipe, fomos compartilhando conhecimentos e experiências, refinando o nosso próprio olhar como pesquisador e aprofundando o nosso suporte teórico e metodológico. No decorrer das análises, fomos igualmente construindo uma interessante relação com "o aprender a pesquisar", através das discussões sobre os estudos de outros sujeitos, tanto em reuniões com o grupo de executores deste projeto quanto em encontros de outros grupos de pesquisa, nos quais compartilhamos saberes, levantamos questões e reflexões voltadas para a pesquisa em nossa área.

De acordo com os dados analisados, as inúmeras experiências vividas pelos mestrandos durante o período de formação na Universidade, em nível de Graduação, foram as principais fontes de saber para as escolhas teórico-metodológicas de seus projetos. Assim, a construção de seus objetos de estudo, que inclui não apenas o tema a ser estudado, mas também a fundamentação teórica e metodologia, foi provocada, assim como no nosso caso, a partir de questões levantas em grupos de estudos dos quais participaram e da atuação de alguns dos sujeitos em programas de bolsas de iniciação acadêmica, como, por exemplo, o PIBIC e o PET. Em acréscimo, a prática como educador em sala de aula, o teste de seleção 
para o Mestrado e a leitura de outros trabalhos referentes ao tema de estudo também foram expostos como fontes de saberes para as decisões teórico-metodológicos do projeto de pesquisa.

Nesse processo, além dos aspectos psicológicos relativos ao desejo e à expectativa de contribuir para a melhoria da prática educacional, toma assento também uma atividade cognitiva que envolve conhecimentos relativos à escolha do tema, à articulação entre as questões e os objetivos da pesquisa, assim como à adequação dos elementos teóricometodológicos a essas questões e aos objetivos levantados. Portanto, necessária se faz uma relação de coerência e de viabilidade entre as orientações teórico-metodológicas da investigação, a fim de que o trabalho científico não responda somente às questões da pesquisa, mas traga igualmente, com essas respostas, resultados viáveis e melhorias para o âmbito escolar, como delinearam os posicionamentos aqui analisados. Sem isso, não há sentido para o fazer da pesquisa para os sujeitos.

Nessa direção, podemos concluir que, mesmo no início de sua formação como pesquisador, os sujeitos já se dão conta de que é preciso haver uma relação de viabilidade entre as orientações teórico-metodológicas e a realidade prática do fazer-pesquisa para que os resultados do trabalho possam gerar uma solução viável aos problemas que se apresentam na realidade estudada. Pelo que pudemos captar das explicações dadas por eles, essa realidade corresponde mais especificamente à prática pedagógica nas escolas, talvez por ser este, para eles, um espaço mais carente de atenção na realidade de nosso país. O que esses sujeitos deixam transparecer em suas intenções de pesquisa é que todo o seu esforço, isto é, toda a sua mobilização acerca do "saber-fazer-pesquisa", parece estar ligado diretamente ao desejo de que a pesquisa possa produzir saberes que concretizem a tão sonhada qualidade no trabalho docente. Portanto, o sentido mais acentuado pelos mestrandos em relação ao aprender fazer pesquisa no campo da Educação parece estar mobilizado pelo desejo de contribuir com a pedagogia dos atores escolares e, por conseguinte, com o incremento das práticas educacionais que têm sua base no "chão da sala de aula".

\section{REFERÊNCIAS}

BOURDIEU, P. Razões práticas: Sobre a teoria da ação. São Paulo: Papirus, 1996.

CHARLOT, B. Da relação com o saber: elementos para uma teoria. Porto Alegre: Artmed, 2000 . 
CHARLOT, B. A noção de relação com saber: bases de apoio teórico e fundamentos antropológicos. In. CHARLOT, B. (Org.). Os jovens e o saber: perspectivas mundiais. Trad. Murad, Fátima. Porto Alegre: Artmed, 2001, p. 15-31.

CHARLOT, B. Relação com o saber, formação dos professores e globalização: questões para a Educação hoje. Porto Alegre: Artmed, 2005.

FREITAS, M. T. A. A perspectiva sócio-histórica: uma visão humana da construção do conhecimento. In: FREITAS, M. T. A.; JOBIM E SOUZA, S. ; KRAMER, S. (Org.).

Ciências Humanas e Pesquisa: Leituras de Mikhail Bakhtin. São Paulo: Cortez, 2003, p. 2638.

GATTI, B. A. A construção da pesquisa em Educação no Brasil. Brasília: Plano Editora, 2002.

MATOS, K. S. L.; VIEIRA, S. L. Pesquisa educacional: o prazer de conhecer. 2. ed. rev. e atual. Fortaleza: Edições Demócrito Rocha, 2002.

SÁ, C. P. de. A construção do objeto de pesquisa em representações sociais. Rio de Janeiro: EdUERJ, 1998. 